\title{
The endogenous determination of retirement age and Social Security benefits*
}

\author{
Francisco Cabo ${ }^{\dagger} \quad$ Ana García-González ${ }^{\ddagger}$ \\ University of Valladolid University of Valladolid
}

May 23, 2012

\footnotetext{
*The authors have been partially supported by MICINN under project ECO200801551/ECON. Most of this research was done during the authors' stay at GERAD. The authors are grateful to Rodney Beard, Jacek Krawczyk, Guiomar Martín-Herrán and Georges Zaccour and his students for their useful discussions and comments.

†Dept. Economía Aplicada (Matemáticas). Tel. 34-983186662. Fax. 34-983423299. e.mail: pcabo@eco.uva.es

‡Dept. Economía Aplicada (Matemáticas). Tel. 34-983186566. e.mail: anagar@eco.uva.es.
} 
Running head: Retirement age and Social Security benefits

Corresponding author: Francisco Cabo.

Dept. Economía Aplicada (Matemáticas).

Avda. Valle Esgueva 6, 47011 Valladolid, Spain.

Tel.: (34)983186566. Fax.: (34)983423299. e.mail:pcabo@eco.uva.es. 


\begin{abstract}
An ageing population in modern societies has put stress on public pension systems. To prevent Social Security deficits from increasing to unbounded stocks of public debt we focus on two policies: reducing the generosity of pension benefits, determined by the government, and postponing the effective retirement age, chosen by employees. An atomistic employee would disregard the effect of his retirement decision on the public debt and would retire as soon as possible. Conversely, an ideal farsighted agency considering all current and future employees would postpone retirement, thereby alleviating the pressure on public debt and allowing for a more generous long-run pension. The government may design a proper incentive strategy to induce myopic atomistic decision-makers, to act non-myopically. This strategy is a two-part incentive with non-linear dependence on the stock of public debt. It is credible if deceiving employees slightly adjust their retirement age decisions to increments in the public debt.
\end{abstract}

keywords: Public pension system, effective retirement age, differential games, credibility of incentive equilibrium. 


\section{Introduction}

Social Security systems in many developed countries are currently in a process of change. An ageing population in these industrialized countries has put their Social Security systems under stress. The percentage of employees reaching retirement age has been growing simultaneously with further life expectancy at retirement age. Furthermore, population growth has slowed down. Therefore, the dependency ratio defined as the number of retirees over the total labor force reveals an upward sloping tendency.

A wide variety of reforms has been proposed. The literature on Social Security reforms is ample and includes debates on structural reforms such as moving from a pay-as-you-go system (PAYG) to an entirely or partially funded system, switching from defined benefit plans to defined contribution plans, or even changing to privately managed or funded Social Security systems (see, for example, Banks and Emmerson (2000)). Yet another alternative focuses on offering a complementary private pension. Nevertheless it is not our intention to discuss pension system design. Conversely, our aim is to study a "parametric" reform (see Banks and Emmerson (2000)) while leaving unchanged the framework found in a PAYG purely public pension system with defined benefits. Two policies which reduce the pressure associated with ageing population on the Social Security systems are included in our study: a delay in the retirement age and a reduction in the generosity of pension benefits.

Most industrialized countries have already attempted to lower public pension benefits ${ }^{1}$ and encourage labor participation at advanced ages. Flexibility in retirement ages (early or late retirement) is currently an accepted practice in many OECD countries. Furthermore, as pointed out in Casey et al. (2003) in some countries early retirement is becoming more costly, while in others late retirement is being more strongly encouraged. ${ }^{2}$ We must be precise here and distinguish between the legal and the effective retirement age. In this paper we will focus on the latter and the mechanism or incentives that might push employees to extend retirement beyond the legal retirement age. Hence, we will 
study decision process by employees regarding their effective retirement age.

The optimal determination of the effective retirement age by individual agents has been analyzed in the literature (see, for example, Heijdra and Romp (2009) or Sánchez Martín (2010) and references therein). In these models individual agents maximize their lifetime utility subject to their lifetime budget constraint. They choose a lifetime path of consumption and their optimal retirement age. However, public pensions are determined by a given formula known by these agents. We are unaware of any study concerning the interaction between the individual agent's decisions on retirement and the government decision on pension generosity. Further this interaction has to be studied in a dynamic setting, because public pension expenses influence the evolution of the public debt and therefore the welfare of future generations. To quantify this effect, notice that social protection is the largest block of public expenditures (accounting for 36.7/18.9/34.2/34.3\% (Eurozone/U.S./Japan/OECD)). And among the social protection benefits, a majority of the OECD countries expenditures was directed to old age: $22.3 / 16.3 / 24.3 / 16.6 \%$ of total government expenditures in 2007; or equivalently 9.6/6/8.8/7 \% of GDP. Further, the relative magnitude of pension expenses on the government accounts will increase as shown by the projections for the next half a century: 13.9/\#/4.8/11.4 \% of GDP in the year $2050 .^{3}$

A dynamic game between the government and a representative consumer concerning the provision of a public good has been analyzed (for example, see Xie (1997), Karp and Lee (2003) or Cellini and Lambertini (2007)). In these papers the public good depends on the tax chosen by the government and the actions of the entire population, while the evolution of the state (agent's wealth) is dependent on individual decisions. On the contrary, in this paper each agent's public pension is dependent on government benefit levels and the retirement age chosen by this particular individual, while an atomistic decision-maker has no influence on the state of the system, defined as the public debt generated by the Social Security system. This state variable will depend on retirement decisions in a full context. The research question in this paper is: assuming that the government cannot determine the effective retirement age, and given that it is 
optimally chosen by employees, could public pensions be settled as an incentive strategy inducing the workforce to behave in a certain way? More precisely, could the government induce myopic employees to behave as if they were nonmyopic? That is, could the government encourage myopic employees, for whom retirement age has a negligible effect on the public debt, to (still maximizing their current utility) take the same decision that would be taken by a nonatomistic decision-maker who is aware of how retirement age may alleviate the problem of a high stock of public debt? Because the incentive-linked behaviour of employees would be beneficial to future generations, this question makes sense for a government concerned on intergenerational equity.

The mechanism considered involves incentive strategies. An incentive strategy can be regarded as one player's announcement that he will stick to a desirable solution (usually the cooperative solution) as long as the other player does not depart from his position in this desired solution. The use of a linear incentive strategy to enforce cooperation in a dynamic game was first introduced by Ehtamo and Hämäläinen (1993, 1995), and later applied, for example, in Jørgensen and Zaccour (2001a,b). The important issue of the credibility of such incentive strategies is analyzed in Martín-Herrán and Zaccour (2005, 2009) for linear-state and linear-quadratic differential games. In the present paper, the incentive strategy does not seek cooperation but instead induces myopic atomistic individuals to act non-myopically. Further, because the incentive strategy is non-linear with regards to the stock of public debt, the punishment to employees who deviate from the non-myopic solution will be dependent on this stock.

The paper presented here is related to three streams of the literature. It enriches the literature on the optimal determination of the effective retirement age by giving entrance to the strategic interaction between the worker's decision and the government choice on the generosity of the public pension. As far as we know, this is the first attempt to study this interaction as a dynamic game. The paper is also a contribution to the literature on incentive strategies. The punishment to the player who deviates from the targeted solution depends on 
the size of the deviation as it is standard in this literature. Moreover, the novelty of our paper is that the punishment also depends on the state of the system, allowing the government to tighten the punishment as the burden of a higher stock of public debt aggravates.

The remainder of the paper is as follows. Section 2 analyzes the scenario of a myopic representative worker who disregards the effect of his effective retirement decision on the dynamics of the public debt. He will choose not to postpone retirement since he has no further incentive from the government to do so. Section 3 studies a benchmark ideal scenario, where the decision on effective retirement age no longer corresponds to individual agents, but instead to an agency who decides on their behalf. This agency is not only concerned with all current workers' welfare but also on future employees'. Thus, this agency acts non-myopically, and a delay in the retirement age, which would help reduce public debt, might arise. In Section 4 we propose an incentive strategy through which the government can induce myopic atomistic decision-makers to behave just like the non-myopic agency, which internalizes the effect of effective retirement age on the dynamics of the public debt. Section 5 analyzes the credibility of such an incentive strategy. Finally, Section 6 concludes.

\section{The model}

Our starting point is a situation where, because of an ageing population, current contributions to the Social Security system are not enough to maintain unaltered the previous level of public pension benefits. The public pension system has switched from a situation characterized by a balanced budget to a situation where pension expenses for retirees exceed contributions from current workers. Everything else remaining equal, the deficit in the Social Security program would fuel unbounded public debt.

Here we consider two policies that may help to adjust contributions and pension expenses: a reduction in public pension benefits and a postponement of the retirement age. The interaction between these two decision variables is 
analyzed in the context of a game of infinite duration between a continuum succession of identical private agents and the government. Agents belonging to the cohort that reaches its legal retirement age at time $t$, decide how much longer to postpone effective retirement. As for the government, it chooses the generosity of the public pension. That is, it decides the retirement pensions as a constant lifetime annuity for this particular cohort. Further, for simplicity we assume that the government pays at time $t$ the actual value of this annuity (one might think that this amount is paid to an insurance company).

Current pension expenses influence future generations through their effect on the evolution of the public debt. For simplicity we neglect any other government expenditures except public pension cost. Thus, the evolution of the public debt depends on the gap between current contributions to the Social Security system and public pension expenses. These expenses depend on the public pension, that the government agrees to pay to every retiree, and the size of this collective. $^{4}$

\section{Public debt dynamics.}

We define $\hat{p}$ as the public pension per capita which, assuming all workers retire at the legal retirement age, could be financed by current contributions. Now if we define public pension as $P(t)=\hat{p}+p(t)$, variable $p(t)$ is the excess or supplementary pension above $\hat{p}$, henceforth called excess-pension. Contributions cancel out $\hat{p}$, and hence we may reduce notation and focus on the excess-pension above contributions. If the government wishes to maintain previous benefit levels (those paid before the process of ageing population), it should fix a positive $p(t)$, and if workers fail to delay their effective retirement age, the induced government deficit would increase the public debt.

When workers are allowed to postpone retirement beyond the legal retirement age, the delay, $x(t)$, would reduce government spending along the period from time $t$ to $t+x(t)$. For tractability, we discount all the ongoing savings along the $x(t)$-length period to time $t$. One may argue that the government could borrow the total amount at time $t$ and repay it with the ongoing $x(t)$-length period savings. 
The primary deficit (which does not account for the interest payment on the debt) can be defined as a function of both the excess-pension, and the delay of the effective retirement age beyond the legal retirement age: $f(p(t), x(t)) \equiv$ $f\left(u_{1}, u_{2}\right)$, with $f_{u_{1}}^{\prime}>0$ and $f_{u_{2}}^{\prime}<0$. For tractability we make the simplifying assumption of constant marginal effects of both variables choosing a linear function: $^{5} f(p(t), x(t))=p(t)-\beta x(t)$. Further, the existing debt is financed by issuing public bonds which yield an interest rate, $i$. A negative public debt, called a Social Security trust fund, would yield the same return as the interest paid by public bonds. Thus, the dynamics of the public debt can be written as:

$$
\dot{D}(t)=p(t)-\beta x(t)+i D(t), \quad \beta>0, D(0)=D_{0}>0 .
$$

\section{Employee's objective function.}

We assume the Employees welfare function, $F_{e}()$, to be an additively separable function between the players actions $(x(t), p(t))$ and the state variable, $D(t): F_{e}(p(t), x(t), D(t))=G_{e}(p(t), x(t))-H_{e}(D(t))$, where $G_{e}(p(t), x(t)) \equiv$ $G_{e}\left(u_{1}, u_{2}\right)$ defines how the employee values players actions, and $H_{e}$ measures the damage caused by the public debt. The representative employee who reaches his legal retirement age at time $t$ positively values a supplementary pension, $\left(G_{e}\right)_{u_{1}}^{\prime}>0$, while the opposite occurs with a delay in retirement age, $\left(G_{e}\right)_{u_{2}}^{\prime}<0$. We further assume a constant marginal benefit of the excess-pension, $\left(G_{e}\right)_{u_{1}^{2}}^{\prime \prime}=$ 0 , but an increasing marginal cost on the delay in retirement, $\left(G_{e}\right)_{u_{2}^{2}}^{\prime \prime}<0$. This latter is explained because late retirement not only implies additional "linear" years of labor. The longer the employee delays retirement, the more cumbersome becomes labor, while at retirement, life expectancy shortens and presumably quality of life worsens. For simplicity, we also assume an increasing marginal cost on early retirement. In many countries, early retirement is legally restricted and subjected to monetary penalties. ${ }^{6}$

Furthermore, an employee at legal retirement age does not exclusively value the supplementary or extra-pension paid by the government at that time. The stock of public debt is also valued because it indicates how likely the pension will be maintained, increased or reduced in the forthcoming years. Thus, for 
simplicity, we assume that employees close to retirement value negatively and linearly the current stock of public debt, $\left(H_{e}\right)^{\prime}>0,\left(H_{e}\right)^{\prime \prime}=0$.

For tractability we will assume a linear quadratic structure for the employee's objective function of the form:

$$
F_{e}(p(t), x(t), D(t))=p(t)-\frac{c}{2} x^{2}(t)-h D(t), \quad c, h>0 .
$$

Government's objective function:

An additively separable function between the public debt and the players actions is also assumed for the government, $F_{g}(p(t), D(t))=G_{g}(p(t))-$ $H_{g}(D(t))$.

A delay in the retirement age, $x(t)$, implies lower pension expenses for the government and hence, as explained before, a reduction in the public deficit. Apart from this savings we assume no ulterior effect of $x(t)$ on the government welfare, which hence is not directly affected by the effective retirement age. On the other hand, although an excess-pension enhances retiree welfare, it also boosts the public deficit, which might be regarded by younger employees as a threat to their future pensions. Thus we assume that the expected vote, and hence government welfare, initially increases with the excess-pension, but at a decreasing rate which eventually becomes negative, $\lim _{p(t) \rightarrow 0}\left(G_{g}\right)^{\prime}>0$, $\left(G_{g}\right)^{\prime \prime}<0, \forall p(t) \geq 0$ and $\left(G_{g}\right)^{\prime}<0, \forall p(t) \geq \bar{p}>0$.

The government is also concerned on the level of public debt. Voters, specially younger employees or future entrants in the job pool might perceive high values of public debt as a threat to their future pensions. This idea of voters as fiscal conservatives, tending not to reelect political parties who increase expenditure enhance deficits or inflate public debt, was first introduced by Peltzman (1992) analyzing U.S. elections. Fiscal conservationism is also upheld by other empirical papers like Brender (2003), Brender and Drazen (2005, 2008), or Alesina et al. (1998). This hypothesis seems more realistic in developed consolidated democracies (Brender and Drazen (2005)). A current example of fiscal conservationism or prudent government is the stability pact signed in Maastricht by the European countries adopting the euro. Some countries even include fis- 
cal restraints in the constitutional level. Nevertheless, the empirical evidence is not conclusive. Some studies support that voters reward fiscal profligacy (see, Arvate et al. (2010)). Our point here is that the hypothesis of fiscal conservative voters becomes more likely as the level of public debt rises. Conversely, highly negative stocks of public debt might be perceived by voters as a symptom of mismanagement. Hence, the government is interested in maintaining public debt within certain limits. For simplicity we fix the desired stock of public debt equal to zero $\left(H_{g}\right)^{\prime} \gtreqless 0 \Leftrightarrow D \gtreqless 0$. Further, we assume that the government is well-informed about the effect of increments in the stock of public debt and hence highly sensitive to this changes. The marginal damage caused by the public debt in the expected vote share is assumed increasing with the level of public debt, $\left(H_{g}\right)^{\prime \prime}>0$.

For tractability a linear quadratic structure is also assumed:

$$
F_{g}(p(t), D(t))=p(t)-\frac{q}{2} p^{2}(t)-\frac{\sigma}{2} D^{2}(t), \quad q, \sigma>0
$$

\section{Myopic employees}

A static representative employee who reaches legal retirement age at time $t$, myopically chooses the delay in his effective retirement age. Even an agent with intergenerational altruism (redefined as a continuum of representative employees successively reaching retirement age) would still act myopically. Given that this employee is a representative of a large number of identical agents, he would determine the optimal delay by not taking into account the effect of his decision on the dynamics of the stock of public debt.

The myopic employee maximizes his static welfare,

$$
\max _{x(t)} p(t)-\frac{c}{2} x^{2}(t)-h D(t)
$$

while the government solves the optimal control problem:

$$
\begin{gathered}
\max _{p(t)}\left\{W_{g}=\int_{0}^{\infty}\left(p(t)-\frac{q}{2} p^{2}(t)-\frac{\sigma}{2} D^{2}(t)\right) e^{-\rho t} d t\right\} . \\
\text { s.t.: } \dot{D}(t)=p(t)-\beta x(t)+i D(t), \quad D(0)=D_{0}>0 .
\end{gathered}
$$


For comparison purposes, the government problem is solved using the Hamilton-Jacobi-Bellman (HJB) equation for an autonomous game (see, for example, Dockner et al. (2000)):

$$
\rho V_{g}^{m}(D)=\max _{p}\left\{p-\frac{q}{2} p^{2}-\frac{\sigma}{2} D^{2}+\left(V_{g}^{m}\right)^{\prime}(D)[p-\beta x+i D]\right\}
$$

where $V_{g}^{m}(D)$ denotes the value function of the government when the employee behaves myopically (from this point onwards the time argument is omitted when no confusion can arise). If we conjecture a quadratic value function, using the HJB equation and standard maximization techniques the solution of the problem can be easily found.

Proposition 1. The government value function and the equilibrium strategies of the government and the myopic employee are given by:

$$
\begin{aligned}
& V_{g}^{m}(D)=a_{g}^{m}+b_{g}^{m} D+c_{g}^{m} D^{2}, \\
& x^{m}=0, \quad p^{m}(D)=\frac{1+b_{g}^{m}+2 c_{g}^{m} D}{q},
\end{aligned}
$$

with

$$
\begin{aligned}
& c_{g}^{m}=-\frac{(2 i-\rho) q+\sqrt{(2 i-\rho)^{2} q^{2}+4 \sigma q}}{4}<0, \\
& b_{g}^{m}=-\frac{2 c_{g}^{m}}{2 c_{g}^{m}+q(i-\rho)}<0, \quad a_{g}^{m}=\frac{\left(1+b_{g}^{m}\right)^{2}}{2 q \rho}>0 .
\end{aligned}
$$

The optimal trajectory of the public debt reads:

$$
D_{m}(t)=\left(D_{0}-D_{m}^{*}\right) e^{\gamma_{m} t}+D_{m}^{*},
$$

with

$$
D_{m}^{*}=-\frac{i-\rho}{i q(i-\rho)+\sigma}, \quad \gamma_{m}=\frac{q \rho-\sqrt{(2 i-\rho)^{2} q^{2}+4 \sigma q}}{2 q} .
$$

Corollary 2. Public debt will not converge to its steady-state equilibrium (i.e. $\left.\gamma_{m}>0\right)$, if and only if:

$$
\rho>2 \sqrt{\frac{\sigma}{q}} \wedge i \in\left(r^{-}, r^{+}\right),
$$

with $r^{-} \in(0, \rho / 2)$ and $r^{+} \in(\rho / 2, \rho)$ the roots of the second order polynomial $i^{2} q-i q \rho+\sigma$. 
A comparison of the discount rate versus the rate of return on public bonds reveals whether public debt will converge to a positive or a negative steady state value, or whether it will diverge.

The absence of incentives to postpone retirement encourages the representative employee to retire exactly at the legal retirement age. While the optimal delay in retirement age is constant and equal to zero, the government fixes a public excess-pension which is a function of the time-dependent stock of public debt:

$$
\begin{aligned}
& p^{m}(D)=p_{0}^{m}+p_{1}^{m} D, \quad p_{0}^{m}=-\frac{2(i-\rho)}{\rho q+\sqrt{(2 i-\rho)^{2} q^{2}+4 \sigma q}} \\
& p_{1}^{m}=-\frac{q(2 i-\rho)+\sqrt{(2 i-\rho)^{2} q^{2}+4 \sigma q}}{2 q}<0
\end{aligned}
$$

while this stock, $D$, evolves through time according to (6).

With a zero public debt the government would be willing to supplement the pension that can be paid by current contributions (i.e. $p_{0}^{m}>0$ ) only if the interest payments of the bonds are lower than the discount rate, and viceversa. Further, since $p_{1}^{m}$ is negative, the excess-pension would be lesser when the stock of public debt is higher.

\section{Non-myopic employees. Markovian Nash Equi- librium}

This benchmark scenario assumes that the effective retirement age is not determined by atomistic decision-makers, but there exists an agency which fixes the optimal retirement age to maximize employee welfare. This agency is no longer myopic. Firstly, because it maximizes not only the welfare of employees that currently reach legal retirement age, but also those who will reach this age in the future. And secondly, because it fixes the effective retirement age of all agents belonging to a particular cohort. Hence it is aware of the effect of its decisions on the dynamics of the public debt. Denoting $V_{g}^{N}(D)$, and $V_{e}^{N}(D)$ 
the value functions of the government and the employee, the HJB equations for this game read:

$$
\begin{aligned}
& \rho V_{e}^{N}(D)=\max _{x}\left\{p-\frac{c}{2} x^{2}-h D+\left(V_{e}^{N}\right)^{\prime}(D)[p-\beta x+i D]\right\}, \\
& \rho V_{g}^{N}(D)=\max _{p}\left\{p-\frac{q}{2} p^{2}-\frac{\sigma}{2} D^{2}+\left(V_{g}^{N}\right)^{\prime}(D)[p-\beta x+i D]\right\} .
\end{aligned}
$$

The linear quadratic structure of the game leads us to conjecture quadratic value functions and hence, the game can be solved.

Proposition 3. The value functions and the equilibrium strategies for the government and the non-myopic agency which represents all employees are:

$$
\begin{aligned}
& V_{e}^{N}(D)=a_{e}^{N}+b_{e}^{N} D+c_{e}^{N} D^{2}, \quad V_{g}^{N}(D)=a_{g}^{N}+b_{g}^{N} D+c_{g}^{N} D^{2}, \\
& x^{N}(D)=-\beta \frac{b_{e}^{N}+2 c_{e}^{N} D}{c}, \quad p^{N}(D)=\frac{1+b_{g}^{N}+2 c_{g}^{N} D}{q},
\end{aligned}
$$

with

$$
\begin{aligned}
& c_{e}^{N}=-\frac{c[2 q(2 i-\rho)+\sqrt{\Delta}]}{6 q \beta^{2}}<0, \quad c_{g}^{N}=\frac{-q(2 i-\rho)+\sqrt{\Delta}}{12}<0, \\
& b_{e}^{N}=\frac{-2 c \Theta_{e}+q \beta^{2} \Xi_{e}}{6 q \beta^{2}[i(i+\rho) q+i \sqrt{\Delta}-3 \sigma]}, \quad b_{g}^{N}=\frac{\left\{c \Theta_{g}-q \beta^{2} \Xi_{g}\right\}[(2 i-\rho) q-\sqrt{\Delta}]}{12 c q[i(i+\rho) q+i \sqrt{\Delta}-3 \sigma]}, \\
& a_{e}^{N}=\frac{2\left(1+b_{e}^{N}\right)\left(1+b_{g}^{N}\right) c+\left(b_{e}^{N}\right)^{2} q \beta^{2}}{2 c q \rho}, \quad a_{g}^{N}=\frac{\left(1+b_{g}^{N}\right)^{2} c+2 b_{g}^{N} b_{e}^{N} q \beta^{2}}{2 c q \rho}, \\
& \Delta=(2 i-\rho)^{2} q^{2}-12 \sigma q, \\
& \Theta_{e}=\rho[(2 i-\rho) q-\sqrt{\Delta}]+4 i(2 i-\rho) q+5 i \sqrt{\Delta}-12 \sigma \\
& \Xi_{e}=-(i+\rho)[(2 i-\rho) q-\sqrt{\Delta}]-3 h[(4 i+\rho) q+\sqrt{\Delta}]-6 \sigma \\
& \Theta_{g}=(4 i-5 \rho) q+\sqrt{\Delta}, \quad \Xi_{g}=-6 h q-(2 i-\rho) q+\sqrt{\Delta} .
\end{aligned}
$$

The optimal trajectory of the public debt reads:

$$
D_{N}(t)=\left(D_{0}-D_{N}^{*}\right) e^{\gamma_{N} t}+D_{N}^{*},
$$

with

$$
D_{N}^{*}=-\frac{c\left(1+b_{g}^{N}\right)+q b_{e}^{N} \beta^{2}}{2 c c_{g}^{N}+c i q+2 q c_{e}^{N} \beta^{2}}, \quad \gamma_{N}=-\frac{q(4 i-5 \rho)+\sqrt{\Delta}}{6 q} .
$$


Proof. Maximizing the right-hand sides of equations (7) and (8), the optimal excess-pension and effective retirement age are obtained as affine functions of the stock of public debt. Substituting these equilibrium strategies into the HJB equations lets the coefficients of the value functions to be computed by identification. Two sets of solutions satisfy conditions $c_{i}^{N}<0, i \in\{e, g\}$, and therefore imply concave value functions. We choose the solution with a faster rate of convergence, and a greater set of parameters values for which the steady state equilibrium is stable.

The discriminant, $\Delta$, is positive if either $i<\rho / 2-\sqrt{3 \sigma / q}$ or $i>\rho / 2+\sqrt{3 \sigma / q}$. Since we need $i>\rho / 2$ to guarantee $c_{i}^{N}<0, i \in\{e, g\}$, henceforth we will assume condition:

$$
i>\frac{\rho}{2}+\sqrt{3 \frac{\sigma}{q}} .
$$

Corollary 4. Public debt will not converge to its steady-state equilibrium (i.e. $\gamma_{N}>0$ ), if and only if:

$$
\left(\rho<4 \sqrt{\frac{\sigma}{3 q}} \wedge i<\frac{5 \rho}{4}\right), \quad \text { or } \quad\left(\rho>4 \sqrt{\frac{\sigma}{3 q}} \wedge i<r_{N}^{-}\right),
$$

with $r_{N}^{-} \equiv 3 \rho / 2-\sqrt{\rho^{2}-4 \sigma / q} / 2 \in(\rho, 3 \rho / 2)$ root of the second order polynomial $i^{2}-3 i \rho+2 \rho^{2}+\sigma / q$.

Stability requires the rate of return to be either greater than $5 \rho / 4$ or $r_{N}^{-}$. Both figures are greater than $\rho$. Consequently, a necessary condition for stability, assumed henceforth is:

$$
i>\rho .
$$

As condition $\rho>4 \sqrt{\sigma /(3 q)}$ is equivalent to $r_{N}^{-}<5 \rho / 4$, then a sufficient condition for stability is given by an interest rate sufficiently greater than the discount rate:

$$
i>\frac{5 \rho}{4} .
$$

It can be easily proved that condition (14) implies $i>r^{+}$in Corollary 2 and hence it also guarantees convergence of the public debt when employees act myopically. 
Lemma 5. From condition (11) which guarantees concave value functions, and the stability conditions in (14), it follows that $b_{e}^{N}<0$ and $b_{g}^{N}>0$.

The sign of the public debt at steady state cannot be fully characterized. It will be negative, defining a Social Security trust fund $\left(D_{N}^{*}<0\right)$, under condition $i \in(5 \rho / 4,2 \rho)$. That is, an interest rate sufficiently greater than the discount rate (so that sufficient condition for stability of the pubic debt (14), is fulfilled) but not so greater that $i$ surpasses $2 \rho$.

In a Markovian Nash equilibrium, the optimal delay in the effective retirement age and the optimal excess-pension above contributions are both expressed as affine functions of the stock of public debt.

$$
x^{N}(D)=x_{0}^{N}+x_{1}^{N} D, \quad p^{N}(D)=p_{0}^{N}+p_{1}^{N} D .
$$

Further, from assumption (11) and Lemma 5 it follows that:

$$
x_{0}^{N}=-\frac{\beta b_{e}^{N}}{c}>0, x_{1}^{N}=-\frac{2 \beta c_{e}^{N}}{c}>0, p_{0}^{N}=\frac{1+b_{g}^{N}}{q}>0, p_{1}^{N}=\frac{2 c_{g}^{N}}{q}<0 .
$$

When effective retirement age is not chosen by myopic atomistic decision-makers, but instead by a farsighted agency, this agency would postpone effective retirement beyond legal retirement age, $x_{0}^{N}>0$, if the public debt were zero. Additional positive stocks of public debt would imply longer delays, $x_{1}^{N}>0$. The government with no public debt obligations would pay a public pension exceeding current employees' contributions, $p_{0}^{N}>0$, while in the myopic case (assuming $i>\rho$ ) it chooses a pension below contributions, $p_{0}^{m}<0$. Furthermore, as the problem of the public debt worsens (the stock increases), the government would reduce its generosity, although the marginal reduction is smaller than in the case of myopic atomistic employees, $p_{1}^{m}<p_{1}^{N}<0$. Thus, for any nonnegative stock of public debt, the Markovian Nash equilibrium implies higher pensions for employees than in the myopic scenario. Moreover, numerically we prove that this is true even if the public debt becomes negative, $p^{N}(t)>p^{m}(t)$ at any time $t \in[0, \infty)$.

Let us initially assume a situation characterized by a null stock of public debt, and a population of retirees excessively large in relation to the contribu- 
tions to the Social Security. A government confronted with myopic employees (who retire as soon as they reach the legal retirement age) would fix a public pension below contributions. Conversely, if employees behave as non-myopic agents and delay retirement, the pressure of pension expenses on the public deficit is alleviated and the government may compensate these employees with a higher pension. This compensation coming from longer delays in retirement is stronger for positive stocks of public debt and weaker for negative stocks.

As for the public debt, the convergence to its steady-state value is slower when the retirement age is determined by a farsighted agency, $\gamma_{m}<\gamma_{N}<$ 0. However, the public debt reached in the long run is lower than the stock reached when myopic employees make retirement decisions. Given that steadystate values of public debt cannot be analytically compared, we have relied on numerical simulations to prove that $D_{N}^{*}<D_{m}^{*}$.

\section{$4.1 \quad$ Numerical analysis}

Numerical analysis has been required to prove that in the Markovian Nash equilibrium the public pension is higher, not only in the long run, but also at any time $t\left(p^{N}(t)>p^{m}(t)\right)$, while the stock of public debt converges to a lower value $\left(D_{N}^{*}<D_{m}^{*}\right)$. Furthermore, numerically we prove that the joint welfare (government plus employee welfare) is higher when the decisions on the effective retirement age are taken by a non-myopic agency: $V_{g}^{N}\left(D_{0}\right)+V_{e}^{N}\left(D_{0}\right) \equiv$ $V^{N}\left(D_{0}\right)>V^{m}\left(D_{0}\right) \equiv V_{g}^{m}\left(D_{0}\right)+V_{e}^{m}\left(D_{0}\right)$.

We have proved that, as long as conditions (11) and (14) are satisfied, and solutions are real, the statements above always hold. This has been numerically proven computing $10^{5}$ random points with parameters values following a uniform distribution function within the intervals: $i, \rho \in(0, .02)$, $c \in(0,10), q \in(.01,10), \sigma \in\left(0,10^{-5}\right), h \in\left(0,10^{5}\right)$, and $\beta \in(.1,5)$. The grid of initial values for the stock of public debt being $D_{0} \in\left[-10^{7}, 10^{7}\right]$, to prove $D_{N}^{*}<D_{m}^{*}$ and $p^{N}(t)>p^{m}(t)$; and a narrower $\operatorname{grid}^{7}, D_{0} \in\left[-10,10^{4}\right]$, to prove $V^{N}\left(D_{0}\right)>V^{m}\left(D_{0}\right)$. Hence numerical results are robust to changes in 
parameters' values.

Contrary to the myopic case, where employees leave their jobs when they attain legal retirement age, a farsighted agency would delay retirement when a positive public debt exists, and even when public debt is equal to zero. Hence, the government may provide a greater public pension, and although more slowly, public debt would converge toward a lower stock at the steadystate equilibrium. Moreover, the two agents, government and employee, jointly considered attain a greater welfare. These results can be illustrated for particular parameters' values: ${ }^{8} D_{m}^{*}=-133, D_{N}^{*}=-912269, \gamma_{m}=-0.0032, \gamma_{N}=$ $-0.00021, x_{0}^{N}=630, x_{1}^{N}=0.0245, p_{0}^{m}=-0.374, p_{1}^{m}=-0.0147, p_{0}^{N}=$ $305, p_{1}^{N}=-.0009, V_{g}^{m}=-126, V_{e}^{m}=3712, V_{g}^{N}=-1.5 \times 10^{8}, V_{e}^{N}=$ $2.6 \times 10^{8}$.

While the result commented so far are robust to changes in parameters' values, it is worthy to analyze the marginal variations in the delay in the retirement age, the public pension, the stock of public debt and the value functions. A comparative static analysis is presented in Table 1, which shows the percentage change of these variables (rows) with a $10 \%$ change in parameters (columns). As this table makes clear, the levels reached by all variables are strongly dependent on the interest rate and (with an inverse sign) on the discount rate. A higher interest rate (or a lower discount) contributes to a higher public debt with, in general a lower delay in the retirement age and a smaller public pension. A higher interest rate also lowers welfare except for the government when employees act non-myopically. Special care must also be taken to estimate the effect of the delay on the retirement age on the public deficit, $\beta$, which has a strong influence on both the public pension and the delay in retirement.

\section{Table 1}

In the next section, when no farsighted-agency collects current and future individual sovereignty, we address the question of how the government may induce individual agents to behave as farsighted or non-myopic agents. 


\section{Government incentive to act non-myopically}

In this section, the government announces an incentive strategy with the aim to induce myopic employees to defer retirement in the same way as the farsightedagency does in a Markovian Nash Equilibrium. Since the government is already a farsighted agent, he will be at equilibrium with no need of an equivalent incentive strategy from the employees.

The government announces a public pension dependent on the level of public debt and the actual delay in the effective retirement age. This incentive strategy is assumed linear-quadratic:

$$
\psi(\hat{x}, D)=p^{N}(D)-\phi(D)\left(x^{N}(D)-\hat{x}\right), \quad \phi(D)=\phi_{0}+\phi_{1} D .
$$

The government sticks to his Markovian Nash equilibrium as long as the employee behaves according to this equilibrium. However, if the employee retires before $x^{N}(D)$ the government would punish him. The punishment is dependent on the size of this deviation, $x^{N}(D)-\hat{x}$, but also on the current stock of public debt $\phi(D)$. This allows the government to tighten the punishment as the problem of the public debt becomes more cumbersome (at the optimum $\phi_{1}$ will be positive).

For the incentive strategy in (15), it follows that:

$$
\begin{aligned}
& W_{g}\left(x^{N}(D), p^{N}(D)\right) \geq W_{g}\left(x^{N}(D), \psi(\hat{x}, D)\right), \forall \hat{x} \in \mathbb{R}, \\
& p^{N}(D)=\psi\left(x^{N}(D), D\right) .
\end{aligned}
$$

Since the government is a farsighted agent, $p^{N}(D)$ is his best response to $x^{N}(D)$. Thus, if employees act non-myopically the government cannot do better than playing his Markovian Nash equilibrium. Further, the government incentive strategy when employees act as a farsighted agents equates his Markovian Nash equilibrium.

To characterize the incentive strategy equilibrium, employees assume that the government will behave according to the incentive strategy in (15) and solve the static problem:

$$
\max _{x} \psi(x, D)-\frac{c}{2} x^{2}-h D
$$


while the government solves his standard optimal control problem, in (5) subject to $(1)$.

Proposition 6. The government value function and the equilibrium strategies of the government and the employee for the incentive strategy equilibrium are:

$$
\begin{aligned}
& V_{g}^{i}(D)=a_{g}^{i}+b_{g}^{i} D+c_{g}^{i} D^{2}, \\
& x^{i}(D)=\frac{\phi_{0}+\phi_{1} D}{c}, \quad p^{i}(D)=\frac{1+b_{g}^{i}+2 c_{g}^{i} D}{q},
\end{aligned}
$$

with

$$
\begin{aligned}
c_{g}^{i} & =\frac{-c q(2 i-\rho)+2 q \beta \phi_{1}-\sqrt{\left((2 i-\rho) c-2 \beta \phi_{1}\right)^{2} q^{2}+4 c^{2} \sigma q}}{4 c}, \\
b_{g}^{i} & =\frac{2 c_{g}^{i}\left(c-q \beta \phi_{0}\right)}{q \beta \phi_{1}-c\left(2 c_{g}^{i}+q(i-\rho)\right.}, \quad a_{g}^{i}=\frac{c\left(1+b_{g}^{i}\right)^{2}-2 b_{g}^{i} q \beta \phi_{0}}{2 c q \rho} .
\end{aligned}
$$

The incentive equilibrium is determined by equating $x^{i}(D)$ and $x^{N}(D)$. Hence, by identification it follows:

$$
\phi(D)=\phi_{0}+\phi_{1} D, \quad \phi_{0}=-b_{e}^{N} \beta>0, \quad \phi_{1}=-2 c_{e}^{N} \beta>0 .
$$

Corollary 7. Given this incentive equilibrium strategy it can be proved that $c_{g}^{i}=$ $c_{g}^{N}, b_{g}^{i}=b_{g}^{N}$ and $a_{g}^{i}=a_{g}^{N}$. Consequently, the public pension and the government value function coincide with the Markovian Nash equilibrium, $p^{i}(D)=p^{N}(D)$ and $V_{g}^{i}(D)=V_{g}^{N}(D)$. Further, the dynamic of the public debt matches the Markovian Nash equilibrium as described in (9) and (10), $D_{i}(t)=D_{N}(t)$.

Employees regard the incentive strategy in (15) as a governmental commitment to provide a public pension, $p^{N}(D)$, as long as they stick to the non-myopic retirement age, $x^{N}(D)$. Alternatively, the incentive strategy can be rewritten as a two-part incentive:

$$
\psi(x, D)=p^{x=0}(D)+\phi(D) x,
$$

where $p^{x=0}(D)=p_{0}^{N}-c\left(x_{0}^{N}\right)^{2}+\left[p_{1}^{N}-2 c x_{0}^{N} x_{1}^{N}\right] D-c\left(x_{1}^{N}\right)^{2} D^{2}$ (a second order polynomial in the public debt) would be the excess-pension if the employee 
retirees exactly at the legal retirement age (i.e. $x=0$ ). Further, the government rewards one year retirement deferral with an increment of $\phi(D)$ in the public pension. This incentive increases when the stock of public debt grows, $\phi^{\prime}(D)>0$, while (provided $D>0$ ) the pension at legal retirement age decreases $\left(p^{x=0}\right)^{\prime}(D)<0$. The two-part incentive as expressed in (17) is more evident for employees than the same incentive but expressed as in (15). The former is the way in which some governments presently communicate their incentive strategy. ${ }^{9}$

Assuming that the punishment to employees who deviate from the farsighted behaviour is properly defined (as stated in (16)), employees will fix the optimal delay as if they acknowledge the effect of their retirement decisions on the public debt and further as if they care on how this will affect future generations. Then, Corollary 7 states that the optimal behaviour of the government is to provide the public pension in the benchmark scenario (where the delay in retirement age was determined by a non-myopic agency). This retirement pension coincides with the announced incentive strategy because employees have not deviated from the targeted strategy. Because both players behave like in the non-myopic benchmark scenario, the public debt evolves accordingly and the government attains the same value function. Thus, the incentive strategy is a policy instrument which allows a government (concerned on intergenerational equity), to induce atomistic myopic employees to behave as if they were not myopic.

\section{Credibility of the incentive strategy}

An incentive strategy must fulfill one last property in order to be effective: credibility. If employees do not believe that deviations from the solution aimed by the government (a farsighted behaviour) are inevitably linked to the announced punishment, then fearing no penalization they might deviate from the targeted solution. In that case the incentive strategy would not be effective.

In this section we test the credibility of the incentive strategy when em- 
ployees deviate from the farsighted solution, and the deviating strategy belongs to a given set. For any deviating strategy we test whether it is in the government's best interest to implement the announced incentive strategy or to play his non-cooperative Markovian equilibrium. That is, the incentive equilibrium is credible for any deviating strategies, $\hat{x}$, within a set $\mathbf{X}$ if: $W_{g}\left(\hat{x}, p^{N}(D)\right) \leq W_{g}(\hat{x}, \psi(\hat{x}, D)), \quad \forall \hat{x} \in \mathbf{X}$.

The set $\mathbf{X}$ is defined by considering affine deviating strategies, $\hat{x}=\hat{x}(D)=$ $\hat{x}_{0}+\hat{x}_{1} D$, for which the delay in the retirement age is shorter than in the nonmyopic solution (the stock of public debt fixed), $\hat{x}_{0}<x_{0}^{N}$. Further, we also analyze strategies less sensitive to variations in the level of public debt than the farsighted solution, $\hat{x}_{1}<x_{1}^{N}$. Thus, the set $\mathbf{X}$ can be defined as:

$$
\mathbf{X}=\left\{\hat{x}(D)=\hat{x}_{0}+\hat{x}_{1} D, \mid \hat{x}_{0} \in\left[0, x_{0}^{N}\right), \hat{x}_{1} \in\left[0, x_{1}^{N}\right)\right\} .
$$

Notice that within this set, when the economy is characterized by a positive (or even a null) stock of public debt, employees postpone retirement for a shorter period than a non-myopic employee would do, $\hat{x}(D)<x^{N}(D), \forall D \geq 0$.

We are assuming here, as it is usually done in this literature that the player who deviates, in this case the employee, still follows an affine control. For this type of strategies, next proposition characterizes the credibility of the incentive strategy within a given set $\mathbf{X}$.

Proposition 8. The incentive strategy announced by the government is credible within a set $\mathbf{X}$ if and only if:

$$
W_{g}\left(\hat{x}(D), p^{N}(D)\right) \leq W_{g}(\hat{x}(D), \psi(\hat{x}(D), D)), \quad \forall \hat{x}(D) \in \mathbf{X},
$$

with $\psi(x, D)$ given by (15) and (16).

\section{Equivalently:}

$$
\int_{0}^{\infty}\left\{p_{0}^{N}-\frac{q}{2}\left(p_{0}^{N}\right)^{2}+\hat{D}_{N}(t)\left[p_{1}^{N}-q p_{0}^{N} p_{1}^{N}\right]+\hat{D}_{N}^{2}(t)\left[-\frac{q}{2}\left(p_{1}^{N}\right)^{2}-\frac{\sigma}{2}\right]\right\} e^{-\rho t},
$$

with

$$
\hat{D}_{N}(t)=\left(D_{0}-\frac{p_{0}^{N}-\beta \hat{x}_{0}}{\beta\left(\hat{x}_{1}-\underline{x}_{1}\right)}\right) e^{-\beta\left(\hat{x}_{1}-\underline{x}_{1}\right) t}+\frac{p_{0}^{N}-\beta \hat{x}_{0}}{\beta\left(\hat{x}_{1}-\underline{x}_{1}\right)}, \quad \underline{x}_{1} \equiv \frac{p_{1}^{N}+i}{\beta},
$$


is not greater than

$$
\begin{aligned}
& \int_{0}^{\infty}\left\{\Lambda_{0}-\frac{q}{2} \Lambda_{0}^{2}+\hat{D}(t)\left[\Lambda_{1}-q \Lambda_{0} \Lambda_{1}\right]+\hat{D}^{2}(t)\left[\Lambda_{2}-q\left(\Lambda_{0} \Lambda_{2}+\frac{\Lambda_{1}^{2}}{2}\right)\right]-\right. \\
& \left.\left.\hat{D}^{3}(t) q \Lambda_{1} \Lambda_{2}-\hat{D}^{4}(t) \frac{q}{2} \Lambda_{2}^{2}\right)\right\} e^{-\rho t}
\end{aligned}
$$

with

$$
\hat{D}(t)=\frac{\pi_{2} e^{\Lambda_{2}\left(\pi_{1}-\pi_{2}\right) t}\left(D_{0}-\pi_{1}\right)-\left(D_{0}-\pi_{2}\right) \pi_{1}}{e^{\Lambda_{2}\left(\pi_{1}-\pi_{2}\right) t}\left(D_{0}-\pi_{1}\right)-\left(D_{0}-\pi_{2}\right)} .
$$

where the expressions for $\Lambda_{0}, \Lambda_{1}, \Lambda_{2}, \pi_{1}$ and $\pi_{2}$ (in Appendix) depend on parameters and the magnitude of the deviation from the non-myopic Nash equilibrium.

Proof. See Appendix.

When employees deviate from the desired non-myopic solution (playing an affine strategy within the set $\mathbf{X}$ ), expressions (18) and (19) characterize the value function for a government which does not punish deviation but plays Nash. Equivalently, expressions (20) and (21) characterize its value function if it sticks to the announced incentive strategy. To better compare these two value functions the set $\mathbf{X}$ is split in three disjoint sets: $\mathbf{X}=\overline{\mathbf{X}} \cup \underline{\mathbf{X}}^{\mathbf{C}} \cup \underline{\mathbf{X}}^{\mathbf{D}}$, with $\overline{\mathbf{X}}=\left\{\hat{x}(D) \in \mathbf{X} \mid \hat{x}_{1} \in\left(\underline{x}_{1}, x_{1}^{N}\right)\right\}, \underline{\mathbf{X}}^{\mathbf{C}}=\left\{\hat{x}(D) \in \mathbf{X} \mid \hat{x}_{1} \in\left(\underline{x}_{1}-\rho /(2 \beta), \underline{x}_{1}\right]\right\}$, $\underline{\mathbf{X}}^{\mathbf{D}}=\left\{\hat{x}(D) \in \mathbf{X} \mid \hat{x}_{1} \in\left[0, \underline{x}_{1}-\rho /(2 \beta)\right]\right\}$, (see Figure 1$)$.

\section{Figure 1}

From the definition of $p_{1}^{N}$ follows that $\underline{x}_{1}>0$, while condition (14) guarantees $\underline{x}_{1}<x_{1}^{N}$. Further, from the definition of $\underline{x}_{1}$ and $p_{1}^{N}$ it follows that $\underline{x}_{1}-\rho /(2 \beta)>0$. Therefore, $\overline{\mathbf{X}}, \underline{\mathbf{X}}^{\mathbf{D}}, \underline{\mathbf{X}}^{\mathbf{C}} \neq\{\emptyset\}$.

Next proposition describes the behaviour of the stock of public debt and the government discounted welfare when employees deviate from the non-myopic strategy aimed by the government. Their behaviour depend on whether the government does or does not implement the announced punishment.

Proposition 9. When $\hat{x}(D)$ deviates from $x^{N}(D)$ within the set $\mathbf{X}$ : 
- If the government switches to its Markov perfect equilibrium, $p^{N}(D)$ :

$$
\begin{aligned}
& \left|\lim _{t \rightarrow \infty} \hat{D}_{N}(t)=\hat{D}_{N}^{*}=\frac{p_{0}^{N}-\beta \hat{x}_{0}}{\beta\left(x_{1}^{N}-\underline{x}_{1}\right)}\right|<\infty, \quad \forall \hat{x}(D) \in \overline{\mathbf{X}}, \\
& \left|\lim _{t \rightarrow \infty} \hat{D}_{N}(t)\right|=\infty, \quad \forall \hat{x}(D) \in \underline{\mathbf{X}}^{\mathbf{C}} \cup \underline{\mathbf{X}}^{\mathbf{D}}, \\
& \left|W_{g}\left(\hat{x}(D), p^{N}(D)\right)\right|<\infty, \quad \forall \hat{x}(D) \in \overline{\mathbf{X}} \cup \underline{\mathbf{X}}^{\mathbf{C}}, \\
& W_{g}\left(\hat{x}(D), p^{N}(D)\right)=-\infty, \quad \forall \hat{x}(D) \in \underline{\mathbf{X}}^{\mathbf{D}} .
\end{aligned}
$$

- If the government sticks to the announced incentive strategy, $\psi(\hat{x}(D), D)$ :

$$
\begin{aligned}
& \left|\lim _{t \rightarrow \infty} \hat{D}(t)\right|<\infty, \quad \forall \hat{x}(D) \in \mathbf{X}, \\
& \left|W_{g}(\hat{x}(D), \psi(\hat{x}(D), D))\right|<\infty, \quad \forall \hat{x}(D) \in \mathbf{X} .
\end{aligned}
$$

Proof. See Appendix.

From this proposition immediate follows:

Corollary 10. For any $\hat{x}(D) \in \underline{\mathbf{X}}^{\mathbf{D}}, W_{g}\left(\hat{x}(D), p^{N}(D)\right)=-\infty$, while $\left|W_{g}(\hat{x}(D), \psi(\hat{x}(D), D))\right|<\infty$. In consequence the incentive strategy is credible within the set $\underline{\mathrm{X}}^{\mathrm{D}}$.

Whenever $\hat{x}_{1} \in\left[0, \underline{x}_{1}-\rho /(2 \beta)\right]$, if the government refuses to implement the announced punishment its welfare will decrease with no bound. Conversely, when the punishment is implemented the integral in (20) converges. Hence, if the employees who deviate are rather insensitive (or no sensitive at all) to changes in the stock of public debt, the announced strategy is credible. This reasoning applies independently of the deviations in the delay in the retirement age with zero public debt, as long as $\hat{x}_{0} \in\left[0, x_{0}^{N}\right)$.

Henceforth, we study the case where employees deviate but not so much as to impede the convergence of the government welfare when the punishment is not applied (i.e. $\hat{x}_{1}>\underline{x}_{1}-\rho /(2 \beta)$, or equivalently $\hat{x}(D) \in \overline{\mathbf{X}} \cup \underline{\mathbf{X}}^{\mathbf{C}}$ ). As it is usual in this literature, the complexity inherent in the problem of credibility requires a numerical approach. The analysis is carried out defining a grid in 
$\overline{\mathrm{X}} \cup \underline{\mathrm{X}}^{\mathrm{C}}$, and for all points within this grid ${ }^{10}$ the government attains a higher welfare by switching to his Markovian-Nash equilibrium than by sticking to his announced incentive strategy. Hence, the incentive strategy is not credible within this set $\overline{\mathbf{X}} \cup \underline{\mathbf{X}}^{\mathbf{C}}$. This result is robust to changes in the initial stock of public debt, as well as in variations in parameters' values. ${ }^{11}$

To summarize, if employees who deviate from the non-myopic Nash strategy strongly react to increments in the public debt, then credibility is an issue. Conversely, if (as we believe more realistic) they react mildly to variations in the public debt, i.e. condition (22) in the appendix is fulfilled, the announced incentive strategy is credible. In particular, the incentive strategy is credible if the employees do not react at all to variations in the public debt, $\hat{x}_{1}=0$. This results apply as long as the delay in the retirement age with a zero public debt is not longer than in the non-myopic solution, $0<\hat{x}_{0} \leq x_{0}^{N}$.

\section{Conclusions}

Considering individuals allowed to postpone retirement beyond a legal retirement age, this paper studies the interaction between a reduction in the public pension versus a delay in the retirement age. Myopic employees with no further incentive would choose to retire as soon as they reach legal retirement age. Conversely, non-myopic employees would refrain from immediate retirement, which would reduce the pressure on public accounts, allowing for higher pensions in the long-run. For a government compelled to maintaining low stocks of public debt, providing employees with the possibility to decide their effective retirement age might be helpful if they would behave non-myopically.

The paper defines non-linear incentive strategies as a successful incentive to induce myopic employees to act non-myopically. This strategy can be regarded as an announcement, made by the government, that will pay a higher pension to employees that behave non-myopically; and a lower pension to employees that retire before. The reduction in the retirement pension will be stronger the greater the stock of public debt. Alternatively, this strategy can be regarded 
as a two-part incentive: one defines the public pension at legal retirement age, and the second part raises the pension in a given percentage with additional years at work. A higher stock of public debt has a double effect: it reduces the pension to those employees who retire at exactly the legal retirement age; and it also increases the reward for each year retirement is delayed.

The credibility of the incentive strategy crucially depends on the sensitivity of retirement age decisions to changes in the stock of public debt. If the employees who deviate from the non-myopic strategy do not react or very slightly adjust the delay in the retirement age to increments in the public debt, the incentive strategy would be credible and would induce myopic employees to behave non-myopically. Conversely, if their sensitivity is sufficiently large, we numerically find that the government would be better off by not punishing those employees who deviate and the incentive strategy would not be credible. Then, the government should enforce this incentive strategy by law and/or by binding agreements with other political parties. 


\section{Appendix}

\section{Proof of Proposition 8:}

Expressions (18) and (19) where the employee deviates but the government follows his Markov Nash strategy obtained in Proposition 3, immediately follows from (1) and (5).

When the employee deviates and the government sticks to the linear-quadratic incentive strategy in (15) the optimal value of this incentive is determined in Proposition 6 and equation (16). From (5), expression (20) immediately follows, with

$\Lambda_{1}=p_{1}^{N}-c\left[x_{0}^{N}\left(x_{1}^{N}-\hat{x}_{1}\right)+x_{1}^{N}\left(x_{0}^{N}-\hat{x}_{0}\right)\right], \Lambda_{0}=p_{0}^{N}-c x_{0}^{N}\left(x_{0}^{N}-\hat{x}_{0}\right)$, and $\Lambda_{2}=-c x_{1}^{N}\left(x_{1}^{N}-\hat{x}_{1}\right)<0$ (because in $\mathbf{X}$ condition $\hat{x}_{1}<x_{1}^{N}$ holds).

The dynamics of the public debt is now defined by a second order polynomial in $D$ :

$$
\dot{D}=\Lambda_{0}+\Lambda_{1} D+\Lambda_{2} D^{2}-\beta\left(\hat{x}_{0}+\hat{x}_{1} D\right)+i D
$$

Or equivalently:

$$
\dot{D}=Y_{0}+Y_{1} D+Y_{2} D^{2}
$$

with $Y_{0}=\Lambda_{0}-\beta \hat{x}_{0}, Y_{1}=\Lambda_{1}-\beta \hat{x}_{1}+i$, and $Y_{2}=\Lambda_{2}$. The time path of the public debt in (21) can be obtained from this equation, where $\pi_{1}$ and $\pi_{2}$ are the roots of this second order polynomial:

$$
\pi_{1}=\frac{-Y 1+\sqrt{Y_{1}^{2}-4 Y_{2} Y_{0}}}{2 Y_{2}}, \quad \pi_{2}=\frac{-Y 1-\sqrt{Y_{1}^{2}-4 Y_{2} Y_{0}}}{2 Y_{2}} .
$$

\section{Proof of Proposition 9:}

When employees deviate from the non-myopic strategy and the government does not punish them but switches to its Markovian Nash strategy, $\hat{D}_{N}(t)$ is described by (19). This equation points out that the public debt converges towards a constant steady state value, $\hat{D}_{N}^{*}=-\left(p_{0}^{N}-\beta \hat{x}_{0}\right) /\left(p_{1}^{N}-\beta \hat{x}_{1}+i\right)$ if and only if: $\hat{x}_{1}>\underline{x}_{1}$.

Conversely, for $\hat{x}_{1} \in\left(0, \underline{x}_{1}\right]$ the public debt, $\hat{D}_{N}(t)$, would explode to $+\infty$ or $-\infty$, depending on whether $D_{0}$ is above or below $\hat{D}_{N}^{*}$. Discounted welfare 
in (18) tends towards $-\infty$, under condition $\lim _{t \rightarrow \infty} \hat{D}_{N}^{2}(t) e^{-\rho t}=\infty$, which from (19), is equivalent to:

$$
\hat{x}_{1}<\underline{x}_{1}-\frac{\rho}{2 \beta} .
$$

When employees' deviations are penalized $\hat{D}(t)$ is defined in $(21)$. If deviating strategies belong to $\mathbf{X}, \Lambda_{2}<0$ and $\pi_{1}<\pi_{2}$. Hence, provided that $\pi_{1}$ and $\pi_{2}$ are real, the public debt would always converge towards its steady-state value, $\hat{D}^{*}=\pi_{2}$. In consequence, the integral in (20) always converges. 


\section{Notes}

${ }^{1}$ This reduction usually occurs by increasing the length of the averaging period when computing the regulatory base that is used to calculate the public pension. Since salaries increase with age and/or expertise, a longer averaging period implies a lower pension.

${ }^{2}$ Although for many OECD countries the effective retirement age lies below the legal retirement age, some others have succeeded in pressing their employees to continue working beyond the legal retirement age (see, Whiteford and Whitehouse (2006)).

${ }^{3}$ source: OECD.StatExtracts and OECD (2011), Pensions at a Glance 2011: Retirementincome Systems in OECD and G20 Countries, OECD Publishing.

${ }^{4}$ The number of retirees is dependent on demographic and economic aspects. Here we consider that these two factors have led the economy from a previous situation with a ratio of workers above and below the legal retirement age which maintains a balanced public budget, to a new situation with a much higher ratio (which puts pressure on the pension system). Once in the new situation, we assume the ratio remains constant and unaffected by these two forces. However, if retirement age is flexible, the number of agents above the legal retirement age does not necessarily match the size of the collective of retirees (above the effective retirement age).

${ }^{5}$ We acknowledge that a non-linear effect of a longer delay in retirement would be more realistic. As $x(t)$ increases, the employee's expected lifetime would decrease and so would do the expected government savings, $f_{u_{2}}^{\prime \prime}>0$. One might even argue the existence of multiplicative terms: the higher the excess-pension the greater the reduction in the public deficit with a delay in the retirement age. Nevertheless, we consider a lineal specification of $f(p(t), x(t))$ because it is a necessary requirement in order to have a linear-quadratic structure of the game which Markov perfect solution could be analytically found.

${ }^{6}$ This assumption guarantees that early retirement (not allowed and considered in this paper) would never be optimal for employees.

${ }^{7}$ When the initial stock of public debt is extremely large, $D_{0}>10^{4}$, joint welfare is not necessarily greater when employees are farsighted (this might be caused by numerical errors in the finite approximation of the infinite time horizon integrals). Same result would apply if the public debt were not a burden but the initial situation were characterized by a large Social Security trust fund $\left(D_{0}<-10\right)$.

${ }^{8} i=0.01, \rho=.006, q=1, c=.1, \sigma=10^{-5}, h=10, \beta=.5, D 0=100 ;$.

${ }^{9}$ Here early retirement is punished by the same amount that late retirement is rewarded. However there are other cases in the real world with reduced early retirement but with an absence of late retirement (and its rewards), or where early and late retirement are treated unevenly.

${ }^{10} \hat{x}_{1}=\underline{x}_{1}$ and $\hat{x}_{1}=\underline{x}_{1}-\rho /(2 \beta)$ are excluded from the analysis.

${ }^{11}$ Furthermore, same numerical result also arises when deviating strategies are not assumed affine but affine-quadratic functions of the stock of public deb: $\hat{x}=\hat{x}_{0}+\hat{x}_{1} D+\hat{x}_{2} D^{2}$. 


\section{References}

[1] Alesina, Alberto, Perotti, Roberto and José Tavares (1998) The political economy of fiscal adjustments. Brookings Paper on Economic Activity 1, 197-266.

[2] Arvate, Paulo Roberto, Mendes, Marcos and Alexandre Rocha (2010) Are voters fiscal conservatives? Evidence from brazilian municipal elections. Estudos Economicos 40, 67-101.

[3] Banks, James and Carl Emmerson (2000) Public and private pension spending: Principles, practice and the need for reform. Fiscal Studies 21, 1-63.

[4] Brender, Adi (2003) The effect of fiscal performance on local government election results in Israel: 1989-1998. Journal of Public Economics 87, 21872205.

[5] Brender, Adi and Allan Drazen (2005) Political budget cycles in new versus established democracies. Journal of Monetary Economics 52, 1271-1295.

[6] Brender, Adi and Allan Drazen (2008) How do budget deficits and economic growth affect reelection prospects? Evidence from a large panel of countries. American Economic Review 98, 2203-2220.

[7] Casey, Bernard, Howard Oxley, Edward R. Whitehouse, Pablo Antolín, Romain Duval and Willi Leibfritz (2003) Policies for an ageing society: Recent measures and areas for further reform. OECD Economics Department Working Papers 369.

[8] Cellini, Roberto and Luca Lambertini (2007) Time consistent fiscal policies in a Ramsey economy. Mathematical Social Sciences 53, 296-313.

[9] Dockner, Engelbert, Steffen Jørgensen, Ngo Van Long and Gerhard Sorger (2000) Differential games in economics and management science. Cambridge: Cambridge University Press. 
[10] Ehtamo, Harri and Raimo P. Hämäläinen (1993) A cooperative incentive equilibrium for a resource management problem. Journal of Economics Dynamics and Control 17, 659-678.

[11] Ehtamo, Harri and Raimo P. Hämäläinen (1995) Credibility of linear equilibrium strategies in a discrete time fishery management game. Group Decision and Negotiation 4, 27-37.

[12] Jørgensen, Steffen and Georges Zaccour (2001a) Incentive equilibrium strategies and welfare allocation in a Dynamic Game of pollution control. Automatica 37, 29-36.

[13] Jørgensen, Steffen and Georges Zaccour (2001b) Channel coordination over time: incentive equilibria and crecibility. Journal of Economic Dynamic and Control 27, 801-822.

[14] Heijdra, Ben J. and Ward E. Romp (2009) Retirement pensions, and ageing. Journal of Public Economics 93, 586-604.

[15] Karp, Larry S. and In Ho Lee (2003) Time-Consistent Policies. Journal of Economic Theory 112, 353-64.

[16] Martín-Herrán, Guiomar and Georges Zaccour (2005) Credibility of incentive equilibrium strategies in Linear-State Differential Games. Journal of Optimization Theory and Applications 126, 1-23.

[17] Martín-Herrán, Guiomar and Georges Zaccour (2009) Credible linearincentive equilibrium strategies in Linear-Quadratic Differential Games. In Odile Pourtallier, Vladimir Gaitsgory and Pierre Bernhard (eds.), Annals of the International Society of Dynamic Games: Advances in Dynamic Games and Their Applications 10, pp. 1-31. Boston: Birkhäuser.

[18] Peltzman, Sam (1992) Voters as fiscal conservatives. Quarterly Journal of Economics 107, 327-361. 
[19] Sánchez-Martín, Alfonso R. (2010) Endogenous retiremen and public pension system reform in Spain. Economic Modelling 27, 336-49.

[20] Whiteford, Peter and Edward Whitehouse (2006) Pension challenges and pension reform in OECD countries. Oxford Review of Economic Policy 22, 78-94.

[21] Xie, Danyang (1997) On Time Inconsistency: A Technical Issue in Stackelberg Differential Games. Journal of Economic Theory 76, 412-30. 


\section{Tables and Figures}

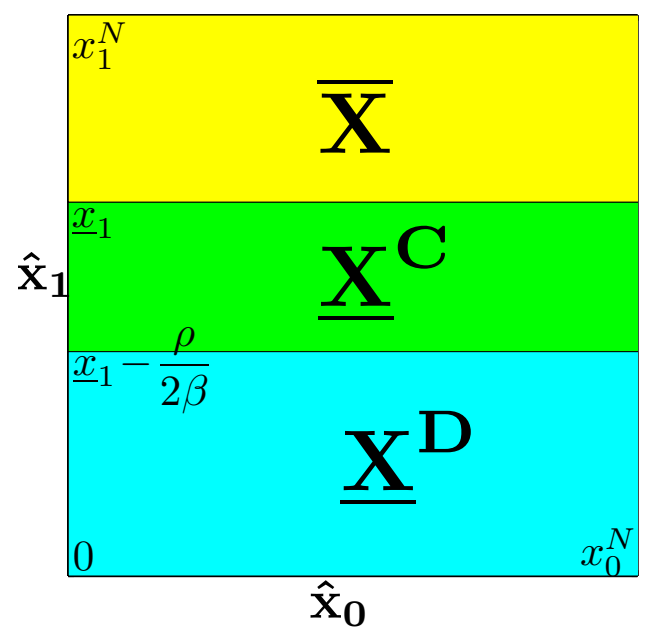

Figure 1: Subsets of $\mathbf{X}$ 


\begin{tabular}{|l|cccccccc|}
\hline & $\Delta i$ & $\Delta \rho$ & $\Delta q$ & $\Delta c$ & $\Delta \sigma$ & $\Delta h$ & $\Delta \beta$ & $\Delta D_{0}$ \\
\hline$\left(\triangle D_{m}^{*}\right) \%$ & 35.6 & -27.5 & 4.6 & 9.1 & -5.9 & -10 & -21 & 0 \\
$\left(\triangle D_{N}^{*}\right) \%$ & 16.7 & -6.2 & 11.8 & 0 & -3.5 & 0 & 0 & 0 \\
$\left(\Delta \gamma_{m}\right) \%$ & -34 & 19.7 & -2.2 & 0 & 2.5 & 0 & 0 & 0 \\
$\left(\triangle \gamma_{N}\right) \%$ & -82.3 & 156 & 47.1 & 0 & -56 & 0 & 0 & 0 \\
$\left(\triangle x_{0}^{N}\right) \%$ & -14.2 & 1.1 & -2.8 & -9.1 & 3.5 & 10 & 10 & 0 \\
$\left(\triangle x_{1}^{N}\right) \%$ & 18.9 & -6 & 1.6 & 0 & -1.9 & 0 & -9.1 & 0 \\
$\left(\triangle p_{0}^{m}\right) \%$ & -15.1 & 15.2 & 8.6 & 0 & 0.6 & 0 & 0 & 0 \\
$\left(\triangle p_{1}^{m}\right) \%$ & -13.1 & 3.9 & 0.4 & 0 & -0.4 & 0 & 0 & 0 \\
$\left(\triangle p_{0}^{N}\right) \%$ & -37.3 & 9.6 & -14.9 & -9.1 & 19.1 & 10 & 21 & 0 \\
$\left(\triangle p_{1}^{N}\right) \%$ & 17.9 & -7.6 & 11.4 & 0 & -13.6 & 0 & 0 & 0 \\
$\left(\triangle V_{g}^{m}\right) \%$ & -1.4 & 1.3 & -0.9 & 0 & 0.1 & 0 & 0 & -11 \\
$\left(\triangle V_{e}^{m}\right) \%$ & -14.7 & -399 & -340 & 0 & 126.9 & 10 & 0 & -253 \\
$\left(\triangle V_{g}^{N}\right) \%$ & 45.6 & -0.3 & 8.4 & 17.3 & -22.5 & -21 & -4.6 & 0.002 \\
$\left(\triangle V_{e}^{N}\right) \%$ & -21.6 & -8.9 & -2.8 & -9.1 & 3.3 & 21 & 21 & -0.004 \\
\hline
\end{tabular}

Table 1: $\%$ change in variables with a $10 \%$ change in parameters 